\title{
EDITORIAL
}

\section{A call for clarity and quality in medical writing}

\author{
Roger Collier B.Eng
}

Cite as: CMAJ 2017 November 20;189:E1407. doi: 10.1503/cmaj.171265

W ords matter in science that matters. Far too often, however, the words in medical literature are chosen and arranged without enough care. This leads to confusing, jargon-filled writing that is difficult to read, even for medical researchers.

Not only is careless writing a barrier to publication, it makes it more difficult for peers to understand and build on other researchers' work. Poor communication limits the impact of medical research, so clinicians and patients ultimately suffer as well. Vague and ambiguous clinical practice guidelines, for example, have been linked to medical errors and inconsistent interpretation. ${ }^{1}$

Writing about complex medical research in plain language is challenging. Technical terms, acronyms and jargon, although used too frequently, cannot be avoided entirely. But the benefits improved knowledge translation, less research waste - are too great for needlessly complicated writing to be accepted as inevitable. Medical educators, academic institutions and health care researchers have a duty to improve the quality of written communication to extend the reach of useful medical knowledge.

Poor writing has always been a problem in medicine. A centuryold editorial in CMAJ suggested there is "probably more bad writing in medical journals than in any other kind of periodical." Five decades later, the problem remained. Quality in scientific writing "seems to have no value in a marketplace that prizes the commonplace and accepts the shoddy," lamented a Canadian researcher in $1964 .{ }^{3}$

Why does this problem remain so prevalent? As is often the case, it's mostly a matter of incentives.

Academic institutions generally reward researchers for publishing often, not for writing well. In some cases, there may be a disincentive to writing clearly. Convoluted language disguises trivial science and pedestrian ideas.

Authors also tend to conform to the language they are used to reading in their fields. Many experts suffer from "the curse of knowledge," which leads to papers full of shorthand and incomplete descriptions. Another problem is that writing comes late in the research process, after months or years of work. Hurry, fatigue, impatience - all are common at this stage, and none make for careful writing.

This is how medical journals end up using many words when one would do. Why say died when you can say experienced a rapidly fatal outcome? This is why polysyllables abound, so we get the words intergenerational, multidimensional, conceptualization, consanguine and conjugality in the same paragraph. Then there are statements so obvious they needn't exist. Is it really necessary to note that unproductive diagnostic measures are unnecessary? ${ }^{4}$

What can be done to improve the quality of writing in medicine? Medical schools and graduate programs in science could offer courses on how to explain complex topics in plain language. Physicians are trained to communicate verbally with patients, but rarely receive instruction on how to communicate better in writing. Academic institutions that employ medical researchers could also provide education and resources on effective communication, and find ways to reward scholars who make an effort to bring their work to a wider audience.

Most of the responsibility for improving writing in academic medicine, however, falls upon the physicians and scientists who produce it. "Our indifference to how we share the fruits of our intellectual labors is a betrayal of our calling to enhance the spread of knowledge," wrote Harvard psychologist Steven Pinker. ${ }^{5}$

Publications such as CMAJ, although far from perfect, do their best to improve confusing medical writing. Many smaller journals lack the resources to edit intensively. So it is not good enough for researchers to rely on others to make their words comprehensible.

It is beyond the scope of this editorial to provide detailed instructions on how to write well. Researchers would be wise to seek out examples of excellent medical writing and learn by imitation. A good guiding principle: strive to be clear, concise and simple enough so as to not befuddle an intelligent nonexpert.

Research requires incredible amounts of time, effort and money - public money, in many cases. Authors who put little effort into presenting their work clearly are doing a disservice to their profession, to the public, and to themselves.

\section{References}

1. Codish S, Shiffman R. A model of ambiguity and vagueness in clinical practice guideline recommendations. AMIA Annu Symp Proc 2005:146-50.

2. Style in medical writing. Can Med Assoc J 1911;1:70-3.

3. Basmajian JV. Quality in scientific writing. Can Med Assoc J 1964;90:1121-5.

4. Fred HL, Scheid M. Thirty-three years of dizzy medical writing and editing. Tex Heart Inst J 2016;43:376-80.

5. Pinker S. Why academics stink at writing. The Chronicle of Higher Education: The Chronicle Review. 2014 Sept. 26. Available: http://stevenpinker.com/files/ pinker/files/why_academics_stink_at_writing.pdf (accessed 2017 Oct. 10).

Competing interests: See www.cmaj.ca/site/misc/cmaj_staff.xhtml

Affiliation: News Editor (Interim), CMAJ

Correspondence to: CMAJ editor, pubs@cmaj.ca 